\title{
Identification of Methicillin Resistance Staphylococcus aureus From Clinical Samples and Environments of a General Hospital in Osogbo
}

\section{${ }^{* 1}$ ADEKUNLE, OC; ${ }^{2} \mathrm{BOLAJI}$, OS $;{ }^{3}$ OLALEKAN, AO; ${ }^{4}$ OYAKEYE, TO}

\author{
${ }^{*}{ }^{*}$ Department of Medical Microbiology and Parasitology, Osun State University, Osogbo, Nigeria \\ ${ }^{3}$ Molecular Diagnostics Research Laboratory, Department of Medical Laboratory Sciences, Faculty of Basic Medical Science, Colle ge of \\ Medicine, University of Lagos, Idiaraba, Lagos ${ }^{4}$ Department of Medical Microbiology and Parasitology, Ladoke Akintola University of \\ Technology, Osogbo, Nigeria \\ *Corresponding Author Email: ocadekunle@lautech.edu.ng,toyintoro@yahoo.com;.Tel.; +2348066586726
}

\begin{abstract}
Infections associated with Staphylococcus aureus (S.aureus) have high mortality rate and lead to economic loss with a long stay in the hospital. Methicillin-resistant Staphylococcus aureus (MRSA) is one of the major nosocomial pathogens which are acquired in the health care facilities. The objective of the study is to investigate the presence of methicillinresistant Staphylococcus aureus (MRSA) in clinical sources and hospital environments. Samples were collected, cultured and identified morphologically. Likewise, the antibiotic susceptibility profile was done. Identification was also done molecularly using PCR (Polymerase Chain Reaction) method. Sixty-three isolates were positive for S. aureus out of 370 clinical samples (urine, wound, nasal swabs and pus) and 37 positives out of 262 samples from hospital environments. Majority of the isolates were sensitive to cefoxitin, novobiocin and majority were resistant to ceftazidine, cloxacillin and augmentin. Seventy-one to ninety- five percent and 51-72\% exhibited multi-drug resistance among clinical samples and hospital environments respectively. Both samples were positive for nис and mec A genes. The detection of methicillin-resistant S. aureus (MRSA) in hospital environments may pose a great danger to patients especially those of compromised status.
\end{abstract}

\section{DOI: https://dx.doi.org/10.4314/jasem.v25i8.19}

Copyright: Copyright (C) 2021 Adekunle et al. This is an open access article distributed under the Creative Commons Attribution License (CCL), which permits unrestricted use, distribution, and reproduction in any medium, provided the original work is properly cited.

Dates: Received: 10 May 2021; Revised: 28 June 2021; Accepted: 01 July 2021

Keywords: Methicillin-resistant Staphylococcus aureus, clinical samples, hospital environments, multidrug resistance

Staphylococcus aureus (S. aureus) is a Gram-positive coccus that occurs in grape-like clusters. It is a eubacterium that is found on the surface of the human skin and mucous membranes (Dilnessa, and Bitew 2016; Gonsu et al., 2013). They are part of the normal microbial flora of the skin, intestinal and upper respiratory tract but may pathogenic for compromised individuals whose defenses have been weakened by illness or therapy. S. aureus is an opportunistic organism in man and animals and is the most frequent cause of nosocomial (hospital) and community infections (Deyno et al., 2017; Omuse et al., 2012). S. aureus have the ability to cause a range of illness from minor skin infections such as abscesses, boils to lifethreatening diseases such as meningitis, pneumonia, sepsis and toxic shock syndrome (TSS) (Ojulong et al., 2008). Isolation of MRSA has been reported from a variety of environmental sites including door handles, floors, linen, gowns, tables, beds, infusion pumps, computer terminals, and ventilation grills (Meyer et al., 2012; Geffers and Gastmeier 2011). Contamination can be widespread in some instances. For example, Boyce et al., 1997 reported the isolation of MRSA from $27 \%$ of surfaces in rooms of MRSA positive patients, with the most common site being flooring. Increasingly, nosocomial isolates are resistant to multiple drugs. In the community, $S$. aureus remains an important cause of skin and soft tissue infections, respiratory infections, and (among injection drug users) infective endocarditis (CDC, 2012). Scientific evidence suggests that environmental contamination plays an important role in the spread of methicillin-resistant S. aureus (MRSA). Therefore, the objective of this study is to investigate the presence of methicillin-resistant $S$. aureus (MRSA) in clinical sources and hospital environments with specific attention to the General Hospital, Asubiaro, Osogbo, Osun State, Nigeria.

\section{MATERIALS AND METHOD}

The materials used were cotton swabs, sterile peptone water, Nutrient agar, Nutrient broth, Mueller Hinton agar, Mannitol salt, autoclave, petri-dishes and ice pack.

Area of Study: The area of the study was Osun State General Hospital, Asubiaro and is located within the 
Osogbo Local Government town of Osun State in the South West Zone of Nigeria.

Ethics Statement: This work was performed according to University ethics committee code of conduct.

Collection of samples: Samples were collected using sterile cotton swabs moistened in sterile peptone water. The swab was firmly applied, slowly rotated and thoroughly covering the surface of the wound. The same was done for patient beds, staff table, door knobs, benches, floors, toilet seats, stretchers, and operation table. The urine sample was collected in a sterile universal bottle. The swab was placed in a sterile nutrient broth, placed in an ice pack, and then taken immediately to the laboratory for culturing.

Preparation of culture media: Nutrient agar, Nutrient broth, Mueller Hinton agar, Mannitol salt agar, were performed according to manufacturers' instructions

Inoculation and incubation: Each sample swab was inoculated into prepared sterile bacterio-logical peptone water and incubated at $37^{\circ} \mathrm{C}$ for $24 \mathrm{~h}$ for enrichment after which the turbid broth was subcultured unto solid differential media such as Mannitol salt agar, and incubated again at $37^{\circ} \mathrm{C}$ for 24 h. Discrete colonies were further subcultured onto freshly prepared plates of the selective media and nutrient agar plates to obtain pure cultures. The purified cultures were gram stained and stored on nutrient agar slants for biochemical tests and identification.

Phenotypic Characterization of the Isolates: S. aureus strains were identified by yellow colony morphology, pigmentation and growth on Mannitol salt agar (Merk). They were identified on the basis of Gram staining and colonial morphology and biochemical tests such as catalase and coagulase. Obtained results were compared with specifications in Bergey'Manual of Systematic Bacteriology

Genotypic Identification of the Isolates: DNA extraction: The DNA of the isolates was extracted by suspending 4-5 bacteria colonies in $500 \mu \mathrm{l}$ of TBE buffer in Eppendorf tubes appropriately labeled. The cells were boiled at $100^{\circ} \mathrm{C}$ for 10 minutes and were cooled rapidly on ice for 30 minutes. $3 \mathrm{ul}$ of Proteinase $\mathrm{K}$ was added to the lysed cells and the mixture was incubated for $15-20$ minutes at $55-60^{\circ} \mathrm{C}$. The enzyme was denatured by boiling at $100^{\circ} \mathrm{C}$ for 10 minutes and was centrifuge at $13,400 \mathrm{rpm}$. The supernatant containing the DNA was collected for PCR and was stored at $-20^{\circ} \mathrm{C}$ for further use. PCR amplification of nuc gene and mecA gene. Primers used are shown in Table 1.

Table 1: Layout of primer used

\begin{tabular}{llllll}
\hline Target & Primer & Sequence & Annealing temp. $\left({ }^{0} \mathbf{C}\right.$ ) & Size & Reference \\
\hline nuc $A$ & nuc $\mathrm{F}$ & GCGATTGATGGTGATACGGTT & 58 & 276 & Goudarzi et al., 2016 \\
& nuc R & AGCCAAGCCTGGCGAACTAAAGC & & & \\
mec $A$ & mecAF & GATCTGTACTGGGTTAATCA & 57 & 500 & (Angela et al., 2015) \\
& mecAR & CATATGACGTCTATCCATTT & & & \\
\hline
\end{tabular}

Gel Electrophoresis: After successful amplification, PCR products were resolved on $1 \%$ agarose gel prepared by dissolving $1 \mathrm{~g}$ of agarose powder in $100 \mathrm{ml}$ of $1 \mathrm{X}$ Tris-borate-EDTA (TBE) buffer solution inside a clean conical flask. The $1 \%$ agarose solution was heated in a microwave oven for 2-3 minutes and was observed for clarity which was an indication of complete dissolution. The mixture was then allowed to cool to about $50^{\circ} \mathrm{C}$ after which $0.5 \mu \mathrm{l}$ of ethidium bromide was then added. It was allowed to cool further and then poured into a tray sealed at both ends with support to form a mould with special combs placed in it to create wells. The comb was carefully removed after the gel had set and the plate was placed inside the electrophoresis tank which contained $1 \mathrm{X}$ TBE solution stained with $1 \mathrm{ug} / \mathrm{ml}$ of ethidium bromide solution and loaded to the well of the agarose gel. The power supply was adjusted to 100 volts for 25 minutes. For each run, a 100 base-pair molecule weight DNA standard (size marker) was used to determine the size of each PCR product. The DNA bands were then visualized with a short wave ultraviolet trans-illuminator and photographed using gene gel bioimaging system. The PCR product was then analyzed.

Antibiotic Susceptibility Testing: The Clinical Laboratory Standard Institute (CLSI) modified disc agar diffusion technique was used for antibiotics susceptibility test. Discrete colonies of confirmed Staphylococcus aureus isolates growing on nutrient agar plates were emulsified in $3 \mathrm{~mL}$ of phosphatebuffered solution and turbidity adjusted to $0.5 \mathrm{McFarland}$ standard. Using a sterile swab stick, the surface of Mueller Hinton agar in a $90 \mathrm{~mm}$ diameter petri dish was inoculated with the bacterial suspension by streaking evenly the whole surface of the agar in three different directions. The inoculated plates were allowed to dry for about 10 minutes before aseptically placing the antibiotic discs to the surface of the agar. They were then allowed to dry for further 30 minutes 
and then incubated at $35^{\circ} \mathrm{C}$. The zones of inhibition produced by each antibiotic disc were measured and the isolates were classified as resistant, intermediate, and sensitive based on the standard interpretative chart of the NCCLS and Fluka zone interpretative chart in accordance with WHO requirement. The Staphylococcus aureus isolates were tested for methicillin resistance using oxacillin disc of $1 \mu \mathrm{g}$ and cefoxitin disc of $30 \mu \mathrm{g}$ and for vancomycin resistance using vancomycin disc of $30 \mu \mathrm{g}$ as recommended by Andrews et al., 2007. Susceptibility of the isolates to other antibiotics namely; ceftazidine $(30 \mu \mathrm{g})$, cefuroxime $(30 \mu \mathrm{g})$, ceftriaxone $(30 \mu \mathrm{g})$, cloxacillin $(5$ $\mu \mathrm{g})$, augumentin $(30 \mu \mathrm{g})$, fusidic acid $(5 \mu \mathrm{g})$, novobiocin $(5 \mu \mathrm{g})$, sulphamethoxazole $(25 \mu \mathrm{g})$, gentamicin $(10 \mu \mathrm{g})$, ofloxacin $(5 \mu \mathrm{g})$ and erythromycin $(5 \mu \mathrm{g})$, was also determined as recommended by Andrews et al., 2007.

\section{RESULTS AND DISCUSSION}

Sixty- three (63) isolates were positive for $S$. aureus out of 370 clinical samples, of which 11 were isolated from 97 urine samples; 21 were isolated from 74 wound samples; 15 isolated from 123 nasal swabs and 16 out of 76 pus samples as shown in Table 2 . In Table 3, out of 20 staff tables 5 were positive, from 40 doorknobs 7 were positive, out of 32 beds 6 were positive, from 21 benches 3 were positive, from 61 different wards' floor 12 were positive, out of 22 toilet seats 1 was positive, from 31 stretchers 3 were positive, of 35 operation tables none was positive for S. aureus totalling $37 \mathrm{~S}$. aureus isolates out of 262 hospital environments. A total of 44 (\%) of Methicillin-resistant $S$. aureus (MRSA) were identified out of $100 \mathrm{~S}$. aureus (63 from clinical samples and 37 from hospital environments). Out of the 44 MRS isolates, $63.6 \%$ (28) from clinical samples and $36.4 \%$ (16) from hospital environments respectively. The majority were sensitive to cefoxitin 79\% (50/63) among clinical samples and 97\% (34/35) from hospital environments as shown in Table 3 and 4 respectively.

Table 2: Positive samples of $S$. aureus among clinical isolates

\begin{tabular}{llll}
\hline Specimen & Sample Size & S.aureus & Percentage distribution (\%) \\
Urine & 97 & 11 & 17.46 \\
Wound & 74 & 21 & 33.33 \\
Nasal swab & 123 & 15 & 23.81 \\
Pus & 76 & 16 & 25.40 \\
Total & 370 & 63 & 100 \\
\hline
\end{tabular}

Table 3: Percentage distribution of S. aureus found in the hospital environments.

\begin{tabular}{llll}
\hline Specimen & Size & S.aureus & Percentage distribution (\%) \\
Staff tables & 20 & 5 & 13.51 \\
Door knobs & 40 & 7 & 18.92 \\
Beds & 32 & 6 & 16.22 \\
Benches & 21 & 3 & 8.1 \\
Floors & 61 & 12 & 32.43 \\
Toilet seats & 22 & 1 & 2.7 \\
Stretchers & 31 & 3 & 8.1 \\
Operation tables & 35 & 0 & 0 \\
Total & 262 & 37 & 100 \\
\hline
\end{tabular}

Table 4: Antibiotic sensitivity profile of $S$. aureus from clinical isolates.

\begin{tabular}{|c|c|c|c|c|}
\hline Antibiotics & $\begin{array}{l}\text { Concentration } \\
(\mu \mathrm{g})\end{array}$ & $\begin{array}{l}\text { No.(\%) } \\
\text { Sensitive }\end{array}$ & $\begin{array}{l}\text { No. (\%) } \\
\text { Resistance }\end{array}$ & $\begin{array}{l}\text { No.(\%) } \\
\text { Intermediate }\end{array}$ \\
\hline Ceftazidime & 30 & $2(3.17)$ & $60(95.23)$ & $1(1.59)$ \\
\hline Cefuroxime & 30 & $9(14.29)$ & 45 (71.43) & $9(14.29)$ \\
\hline Gentamicin & 10 & $32(50.79)$ & $27(42.86)$ & $4(6.35)$ \\
\hline Ceftriaxone & 30 & $9(14.29)$ & $34(53.97)$ & $20(31.75)$ \\
\hline Erythromycin & 5 & $15(23.81)$ & 34 (53.97) & $14(22.22)$ \\
\hline Cloxacillin & 5 & $7(11.11)$ & $56(88.89)$ & 0 \\
\hline Ofloxacin & 5 & 37 (58.73) & $24(38.09)$ & $2(3.2)$ \\
\hline Augmentin & 30 & $10(15.87)$ & $53(84.13)$ & 0 \\
\hline Fusidic acid & 5 & $31(49.21)$ & $32(50.79)$ & 0 \\
\hline Novobiocin & 5 & 46 (73.02) & $11(17.46)$ & $6(9.52)$ \\
\hline Cefoxitin & 30 & $50(79.37)$ & $8(12.70)$ & $5(7.94)$ \\
\hline Oxacillin & 1 & 28 (44.44) & $29(46.03)$ & $6(9.52)$ \\
\hline Vancomycin & 30 & 34 (53.97) & $22(34.92)$ & 7 (11.11) \\
\hline Cotrimoxazole & 25 & $35(55.60)$ & $22(34.92)$ & $(9.52)$ \\
\hline
\end{tabular}

Amplification of confirmatory and the resistant genes: The nuc $A$ and mec A primers used for this PCR are in
(Table 1), and the process was carried out at normal conditions as described earlier. The nис $A$ 
identification gene was observed at 533bp (Fig 1). Resistant gene mec A was observed at 276bp (Fig 2). Seventy six percent (76/100) of the $S$. aureus isolates were positive for $n u c$ gene and thus were categorized as strains of $S$. aureus. All isolates of MRSA were positive for nuc gene. However, 25\% (11/44) of the MRSA were positive for mec $A$ gene.

Table 5: Antibiotic sensitivity profile of $S$. aureus from the environments.

\begin{tabular}{lllll}
\hline Antibiotics & $\begin{array}{l}\text { Conc. } \\
(\boldsymbol{\mu} \text { g) }\end{array}$ & $\begin{array}{l}\text { No. }(\%) \\
\text { Sensitive }\end{array}$ & $\begin{array}{l}\text { No. }(\%) \\
\text { Resistance }\end{array}$ & $\begin{array}{l}\text { No. }(\%) \\
\text { Intermediate }\end{array}$ \\
\hline Ceftazidime & 30 & $35(94.59)$ & $2(5.41)$ & 0 \\
Cefuroxime & 30 & $7(18.92)$ & $27(72.97)$ & $3(8.11)$ \\
Gentamicin & 10 & $22(59.46)$ & $14(37.84)$ & $1(2.70)$ \\
Ceftriaxone & 30 & $12(32.43)$ & $17(45.95)$ & $8(21.62)$ \\
Erythromycin & 5 & $11(29.73)$ & $19(51.35)$ & $7(18.92)$ \\
Cloxacillin & 5 & $24(64.86)$ & $12(32.43)$ & $1(2.70)$ \\
Ofloxacin & 5 & $29(78.38)$ & $6(16.23)$ & $2(5.41)$ \\
Augmentin & 30 & $16(43.24)$ & $21(56.76)$ & 0 \\
Fusidic acid & 5 & $22(59.46)$ & $15(40.54)$ & 0 \\
Novobiocin & 5 & $30(81.08)$ & $3(8.11)$ & $4(10.81)$ \\
Cefoxitin & 30 & $34(91.89)$ & $1(2.70)$ & $2(5.41)$ \\
Oxacillin & 1 & $16(43.24)$ & $14(37.84)$ & $7(18.92)$ \\
Vancomycin & 30 & $20(54.05)$ & $11(29.73)$ & $6(16.23)$ \\
Cotrimoxazole & 25 & $25(67.57)$ & $10(27.03)$ & $2(5.41)$ \\
\hline
\end{tabular}

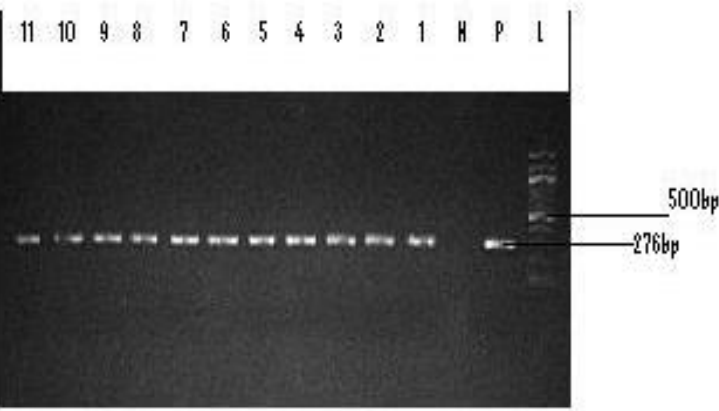

Fig 1: Agarose gel electrophoretogram of nuc gene Methicilinresistant S.aureus after PCR analysis which bands at 276bp Key: L (100 bp ladder); $P$-Positive; $N$-Negative; Lanes 1 -11 are the nuc positive samples of MRSA

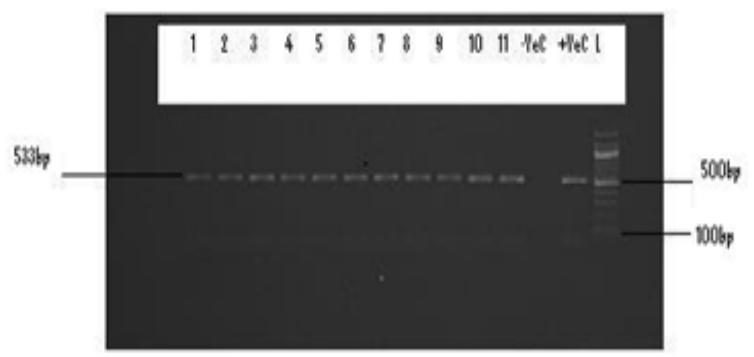

Fig 2: Agarose gel electrophoretogram of $m e c A$ Methicilinresistant $S$. aureus after PCR analysis which bands at $500 \mathrm{bp}$ Key: L -100 bp ladder (DNA marker fragments); Pos - The MRSA positive control; Neg-Negative; Lanes $1-11$ are the mecA positive samples

Hospital is a major reservoir of variety of pathogens. These pathogens are usually normal flora of the human body especially $S$. aureus, which is known to cause nosocomial infection. MRSA strains are often resistant to a wide range of antimicrobials, thereby posing a great danger to those are infected. Especially, those of broken skin or mucous membrane and people with suppressed immune system. Previous hospitalisation, length of hospitalisation, prior and prolonged antibiotic treatment and presence of invasive indwelling devices may be risk factors for MRSA colonisation and infection. Furthermore, the isolation rate was highest from wound discharges (33.3\%), followed by pus $(25.4 \%)$ and nasal swab and urine samples had isolation rates of $23.8 \%$ and $17.5 \%$, respectively. Also, the isolation rate was highest in the hospital floor $(32.4 \%)$, followed by door knobs $(18.9 \%)$ and none was isolated from operation tables. The higher frequency of $S$. aureus isolation in the wound was also observed by Udobi et al., (2013). The prevalence of MRSA in clinical sources and hospital environment is very high $(44 \%)$ when compared with previous report of Gorwitz et al. (2006) in the range of $21 \%-30 \%$ and Nasiru and Kenneth (2018) with $26.9 \%$ though it is similar to what was gotten in Jos (43\%) (Ikei, 2003).The methicillin disc for MRSA detection in these studies might have been responsible for the higher prevalence recorded in them (Taiwo et al., 2004; Onemu and Ophori 2013). That is through the cultural method, the study revealed that 44\% (44/100) of $S$. aureus were tested positive for MRSA. However, when polymerase chain reaction (PCR) for mecA detection was done 11 out of 44 were positive. This may be due to hyperproducing penicillinase strains of $S$. aureus which gave false-positive result for MRSA (Memmi et al.,2008).Resistance to oxacillin was $46.03 \%$ and $37.84 \%$ among clinical isolates and hospital environments respectively. This is in contrast to an Iranian study, where resistance was $88 \%$ among clinical samples. Oxacillin and methicilin are hardly used in our setting as compared with the Iranian study which noted the rampant use of oxacillin. Our report is 
however similar to observations by Olowe et al. and Terry et al. in Osogbo, Nigeria, where $40.4 \%$ of $S$. aureus clinical isolates were resistant to oxacillin (Olowe et al.,2013; Terry et al., 2011). The study also shows that majority of staphylococcal isolates were multidrug resistant, seventy-one to ninety- five percent and $51-72 \%$ exhibited multi-drug resistance among clinical samples and hospital environments respectively. The finding is similar to an observation by Akinjogunla and Enabulele (2010).

Conclusion: Methicillin-resistant S. aureus (MRSA) was identified among clinical samples and hospital environments and this may be reduced by aseptic techniques for all procedures and processes, careful handling of contaminated materials, continuous sterilisation of hospital floors, and proper handwashing technique.

\section{REFERENCES}

Akinjogunla, OJ; Enabulele, IO (2010). Virulence Factors, Plasmid Profiling and Curing analysis of Multidrug Resistant Staphylococcus aureus and Coagulase negative Staphylococcus species isolated from Patients with Acute Otitis Media. $J$. American Science. 6(11):1022-1033

Centers for Disease Control and Prevention (2012). Active bacterial core surveillance (ABCs) report, emerging infections program network, methicillin-resistant Staphylococcus aurous. http://www.cdc.gov/abcs/reportsfindings/survreports/mrsa12.pdf

Deyno, S; Fekadu, S.; Astatkie, A. (2017). Resistance of Staphylococcus aureus to antimicrobial agents in Ethiopia: a meta-analysis. Antimicrobial Resistance and Infection Control, 6(1) 85-87.

Dilnessa, T; Bitew, A (2016).Prevalence and antimicrobial susceptibility pattern of methicillin resistant Staphylococcus aureus isolated from clinical samples at Yekatit 12 Hospital Medical College, Addis Ababa, Ethiopia, BMC Infectious Diseases. 16(1):398-400.

Dulon, M; Peters, C; Schablon, A; Nienhaus, A (2014).MRSA carriage among healthcare workers in non-outbreak settings in Europe and the United States. A systematic review. BMC Infect. Dis.; 14(1):363.

Geffers, C; Gastmeier, P (2011). Nosocomial infections and multidrug-resistant organisms in Germany: epidemiological data from KISS (the
Hospital Infection Surveillance System). Dtsch. ArzteblInt. 108 (6): 8793

Gonsu, KH; Kouemo, SL.; Toukam, M; Ndze, VN; Koulla, SS (2013). Nasal carriage of methicillin resistant Staphylococcus aureus and its antibiotic susceptibility pattern in adult hospitalized patients and medical staff in some hospitals in Cameroon. J. Microbiology and Antimicrobials, 5(3): 29-33.

Gorwitz, J; Jernigan, DB; Powers, JH; Jernigan, JA (2006). Participants in the CDC Convened Experts' Meeting on Management of MRSA in the Community. Strategies for Clinical Management of MRSA in the Community: Summary of Experts Meeting Convenes by the Centre for Disease Control and Prevention.

Ikeh, EI (2003). Methicillin-resistant Staphylococcus aureus (MRSA) at Jos teaching hospital. Afr J Cli Exp Microbiol.4: 52-54.

Memmi, G; Filipe, SR.; Pinho, MG; Fu Z; Cheung, A. (2008). Staphylococcus aureus PBP4 is essential for beta-lactam resistance in community-acquired methicillin-resistant strains. Antimicrob Agents Chemother. 52, 3955-66

Meyer, E; Schroder, C; Gastmeier, P; Geffers ,C (2014).The reduction of nosocomial MRSA infection in Germany: an analysis of data from the Hospital Infection Surveillance System(KISS) between 2007 and 2012. Dtsch. Arzteblint. 111(19): 3316

Nasiru, A; Kenneth, CI (2018): Methicillin-Resistant Staphylococcus aureus in a Central Nigeria Tertiary Hospital. Annals of Tropical Path. 9:610 .

Ojulong, J; Mwambu, T; Jolobo, M (2008).Prevalence of methicillin resistant Staphylococcus aureus MRSA) among isolates from surgical site infections in Mulago hospital-Kampala, Uganda. Internet J. Infectious Dis. 7(2):10326-10330.

Olowe, OA; Kukoyi, OO; Taiwo, SS; Ojurongbe, O; Opaleye, OO; Bolaji, OS (2013). Phenotypic and molecular characteristics of methicillin-resistant Staphylococcus aureus isolates from Ekiti state, Nigeria. Infect Drug Resist. 6:87-92

Omuse, G; Kariuki, S; Revathi, G. (2012).Unexpected absence of methicillin-resistant Staphylococcus aureus nasal carriage by healthcare workers in a tertiary hospital in Kenya. J. Hospital Infect. 80(1): 71-73. 
Onemu OS, Ophori EA. (2013). Prevalence of multidrug resistant Staphylococcus aureus in clinical specimens obtained from patients attending the university of Benin teaching Hospital, Benin City, Nigeria. J Nat Sci Res; 3:154-9.

Taiwo SS, Onile BA, Akanbi AA. (2004). Methicillin-resistant Staphylococcus aureus (MRSA) isolates in Nigeria. Afr J Clin Exp Microbiol; 5:189-97.
Terry OA, Ogbolu DO, Akorede E, Onemu OM, Okanlawon BM. (2011). Distribution of mecA gene amongst Staphylococcus aureus isolates from south western Nigeria. Afr J Biomed Res. $14: 9-16$

Udobi CE; Obajuluwa AF.; and. Onaolapo JA; (2013) "Prevalence and antibiotic resistance pattern of methicillin-resistant Staphylococcus aureus from an orthopaedic hospital in Nigeria," BioMed Res.Inter. 4: 2013. 